\title{
A Study of Rock Magnetism of High-Grade Hematite Ores
}

\author{
William W. Guo \\ School of Engineering \& Technology, Central Queensland University, North Rockhampton, Australia \\ Email: w.guo@cqu.edu.au
}

Received 3 November 2014

\begin{abstract}
Rock magnetism is useful in various applications. Hematite is one of the two most important carriers of magnetism in the natural world and its magnetic features were mostly studied through laboratory experiments using synthetic hematite samples. A gap exists between the magnetic behaviors of hematite contained in the natural rocks and ores and those of synthetic hematite samples. This paper presents the results of a rock magnetism study on the natural hematite ores from the Whaleback mine in the Hamersley Province in the northwest of Western Australia. It was found that high-grade hematite ores carry a much higher remanent magnetization than induced magnetization. Hematite ores with less than $0.1 \%$ magnetite appear to have an exponential correlation between the bulk susceptibility and hematite content in weight percentage, different from the commonly accepted linear relationship between the bulk susceptibility and hematite content obtained from synthetic hematite samples. The new knowledge gained from this study contributes to a better understanding of magnetic behaviors of hematite, particularly natural hematite, and hence applications to other relevant disciplines.
\end{abstract}

\section{Keywords}

Rock Magnetism, High-Grade Hematite Ores, Anisotropy of Magnetite Susceptibility, $Q$-Value, Hamersley Province

\section{Introduction}

Rock magnetism is a study focusing on magnetic features of various natural rocks, including different types of ores. Outcomes of rock magnetism are useful in various applications, such as structural geology [1] [2], mineralogy and materials [3] [4], climate change [5] [6], environment assessment [7], exploration of mineral resources [8] [9], metallurgy [10], and so forth. As one of the two most important carriers of magnetism in the natural world, magnetic features of hematite have been well studied [11]-[14]. Most research outcomes were resulted from laboratory experiments using synthetic hematite samples. Such knowledge is very useful and important in understanding the fundamental magnetic behaviors of hematite. However, there is a gap between the magnetic behaviors of hematite contained in the natural rocks and ores and those of synthetic hematite samples. The former is likely to better reflect specific applications in the real world. 
One key issue in using natural hematite to study its magnetic behaviors is the difficulty of finding pure or high-grade hematite with no weathering effect from the natural world for the study. In most rocks and ores, hematite and magnetite co-exist. Strength of susceptibility of magnetite is about 200 times stronger than that of hematite [3] [4]. When both magnetite and hematite are present, where magnetite is even between 0.1 and 0.5 wt\%, magnetic signatures of magnetite will compress that of hematite.

The Whaleback mine near Newman in the Hamersley Province in the northwest of Western Australia has produced massive high-grade hematite ores, with $>99.5 \%$ hematite in weight from some sections of this mine. The open-pit has cut hundreds of meters deep down to the ground, making fresh hematite ore samples available for the studies of magnetism of natural hematite. This paper presents the results of such a rock magnetism study on the natural hematite ores from the Whaleback mine. New knowledge gained from this study contributes to a better understanding of magnetic behaviors of hematite, particularly natural hematite, and hence applications to other relevant disciplines.

\section{Whaleback Hematite Ores}

The Whaleback iron ores are called martite-microplaty hematite ore or $\mathrm{M}$-(mpl H) ore. The microplaty form of hematite is a diagnostic feature of these ores. These ores only occur in open-pit tens to hundreds of meters deep down from the surface. Ores from the shallow zones may contain significant goethite and thus are called the martite-microplaty hematite-goethite ore or M-(mpl H)-g ore, which is not the focus of this study.

Hematite samples used in this study were collected from the fresh cut of open-pit of the Whaleback mine (Figure 1). Oriented hematite blocks were taken from the cut and later prepared to standard drill-core specimens in the laboratory. XRD analyses proven that all these hematite ores have at least $99.5 \%$ hematite in weigh without goethite and detectable amount of magnetite [3].

\section{Magnetic Features of Hematite Ores}

\subsection{Magnetic Minerals}

Both thermal demagnetization and susceptibility experiments clearly show that hematite is the predominant magnetic mineral in these ores. In Figure 2, the sharp drop of magnetization around $675^{\circ} \mathrm{C}$ indicates the sole presence of hematite. Although a trace of magnetite may also exit in these ores revealed by thermal susceptibility experiments [4], it must be less than $0.1 \%$ in weight in the ores.

\subsection{Mean Bulk Susceptibility}

M-(mpl H) ores collected from the Whaleback mine exhibit a logarithmic normal distribution (Figure 3). The mean bulk susceptibility of $72 \mathrm{M}-(\mathrm{mpl} \mathrm{H})$ ore specimens is $324 \times 10^{-5}$ SI with a standard deviation of $152 \times$ $10^{-5} \mathrm{SI}$. In a few ores that have been affected by later dolerite dykes contain small amounts of secondary magnetite, which results a significant higher susceptibility of up to $1088 \times 10^{-5}$ SI. These ores have been excluded from the statistics for the mean bulk susceptibility of $\mathrm{M}-(\mathrm{mpl} \mathrm{H})$ ores.

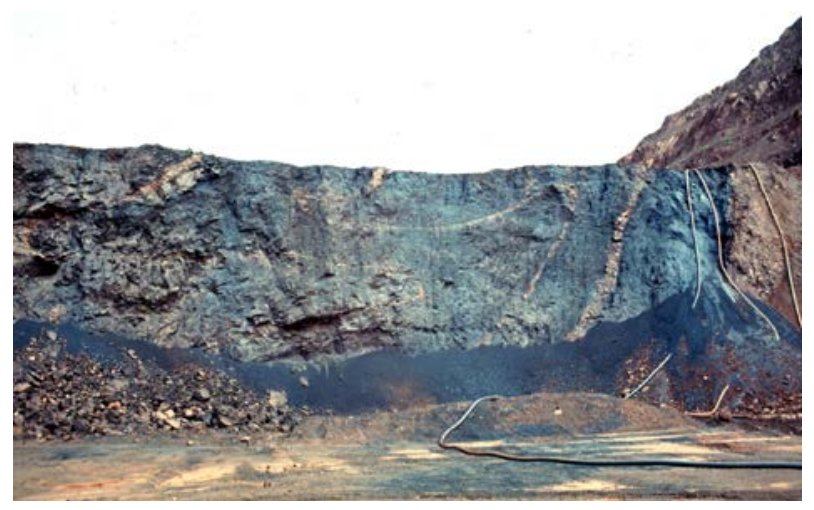

Figure 1. Open cut of Whaleback mine where hematite samples were taken for this study. 


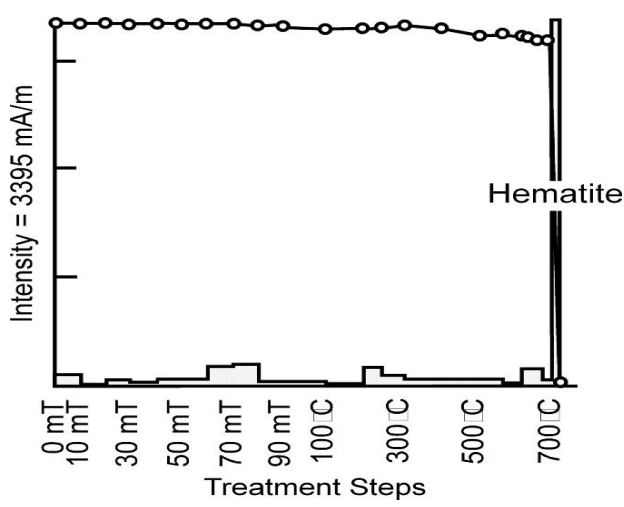

Figure 2. Thermal demagnetization curve of $\mathrm{M}-(\mathrm{mpl} \mathrm{H})$ ore.

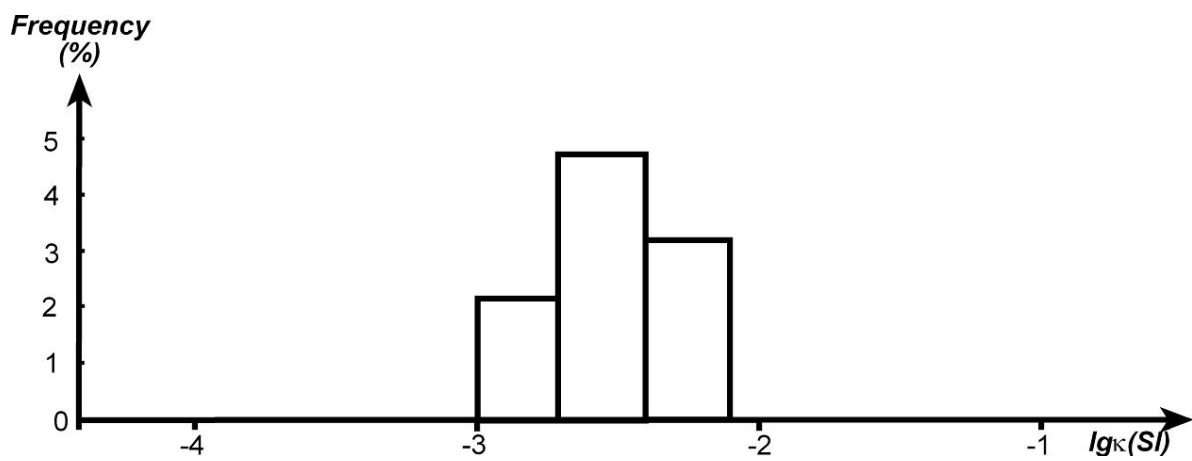

Figure 3. Frequency histogram of bulk susceptibility of M-(mpl H)-g ores.

\subsection{Anisotropy of Magnetic Susceptibility (AMS)}

$\mathrm{M}$-(mpl H) ores show a weak AMS with an average degree of anisotropy of 1.04. The M-(mpl H) ores are generally isotropic in susceptibility but a recognisable sub-bedding-parallel magnetic foliation can be seen in these ores (Figure 4). This indicates the inherited layered magnetic features of these $\mathrm{M}$ - $(\mathrm{mpl} \mathrm{H})$ from their parent rocks of banded iron formations (BIFs) that have a strong AMS of higher than 1.2 (Figure 4) [3].

\subsection{Natural Remanent Magnetization (NRM)}

The NRM of M-(mpl H) ores at Whaleback mine varies from 641 to $1130 \mathrm{~mA} / \mathrm{m}$. However, the orientation of NRM of ores changes according to the geological structural locations where the ores were taken from. In other words, no unique NRM concentration can be determined from these ores taken from different locations in the mine without structural correction.

\section{5. $Q$-Value or Koenigsberger Ratio}

The $Q$-value or Koenigsberger ratio of rocks and ores is defined as the ratio of their remanent magnetization $\left(J_{r}\right)$ to induced magnetization $\left(J_{i}\right)$, i.e.,

$$
Q=\frac{J_{r}}{J_{i}}=\frac{J_{r}}{\kappa F_{0}}
$$

where $F_{0}$ is the intensity of the Earth's Magnetic Field (EMF), and $\kappa$ is the susceptibility of a sample or the mean susceptibility of a site or a rock unit. The EMF shows only a little variation across the Hamersley Province, so an average $F_{0}$ of $54,000 \mathrm{nT}$ is used for the whole region [1]. The average $Q$-value of $\mathrm{M}$-(mpl H) ores in the Whaleback mine is 7.9 with a range varying from 1 to 28 . This means the remanent magnetisation is generally much stronger than the induced magnetization in $\mathrm{M}-(\mathrm{mpl} \mathrm{H})$ ores in the Whaleback mine. The fresh magnetite bearing BIFs, from which the $\mathrm{M}$ - $(\mathrm{mpl} \mathrm{H})$ ores were derived, only have an average $Q$-value of 0.65 [15], meaning the remanent magnetisation carried by magnetite is generally smaller than its induced magnetization. 


\section{Relationship between Bulk Susceptibility and Hematite Content}

Figure 5 shows the correlation between the bulk susceptibility and hematite in wt\% in ores that contain less than $0.1 \%$ of magnetite. The bulk susceptibility in these samples appears to have a good correlation coefficient of +0.6569 with the weight percentage of hematite for the following exponential law:

$$
\kappa_{b}=0.00048 \times 10^{0.00738 W}(\mathrm{SI}) \quad(30 \leq W \leq 100)
$$

This is different from the linear relationship between the bulk susceptibility and hematite obtained from synthetic hematite samples [12].

In theory, the inversion of this correlation could be used for estimating hematite content or grade of hematite ores through quick magnetic susceptibility measurements over the ores. However, such estimation would be with large errors due to the roughness of this correlation. Other means such as neural networks can achieve much more accurate estimate through the inverse mapping [16] [17].

\section{Conclusions}

This study on natural high-grade hematite ores has resulted in the following new findings:

- BIF-derived high-grade hematite ores have a weak anisotropy in magnetic susceptibility with a recognizable sub-bedding parallel magnetic foliation. This is likely inherited from the layered magnetic structure of its parent BITs.
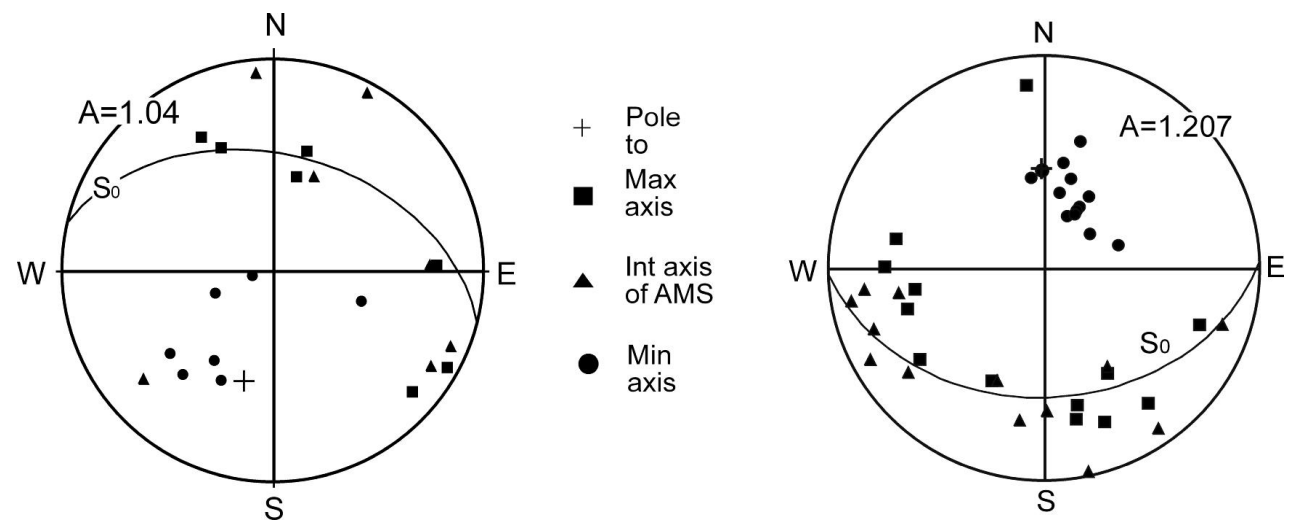

Figure 4. Anisotropy of magnetic susceptibility (AMS) of M-(mpl H)-g ores (left) and BIFs (right). $\mathrm{S}_{0}$ is bedding plane.

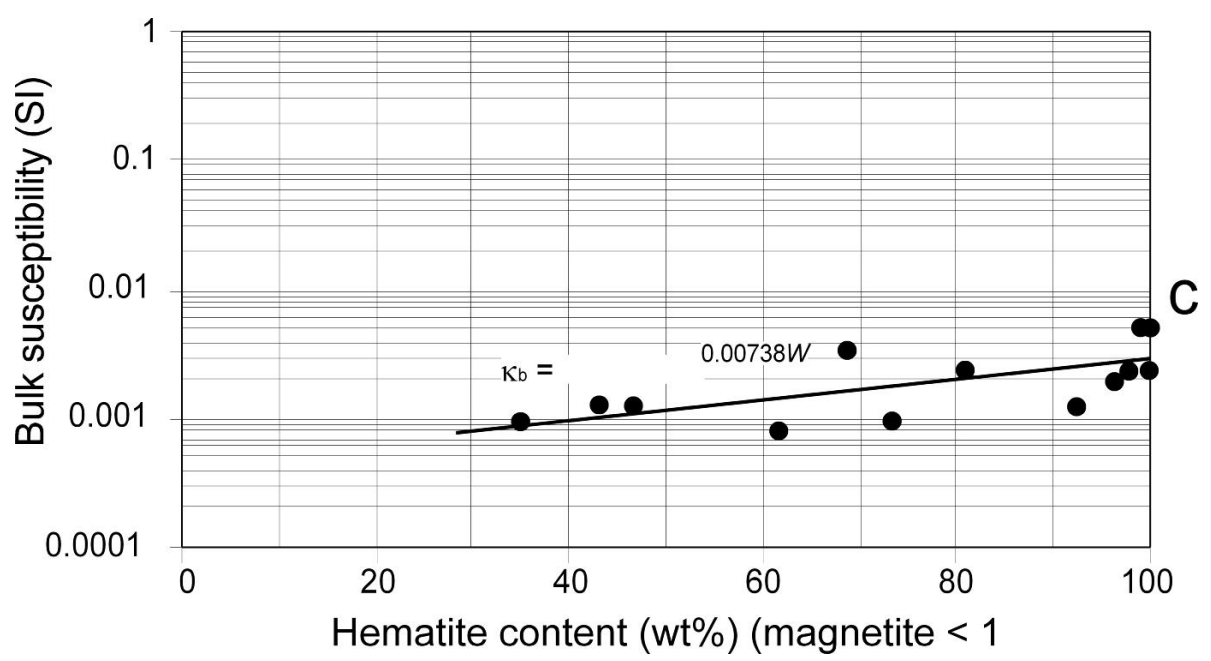

Figure 5. An exponential correlation between bulk susceptibility and hematite content in samples with $<0.1 \%$ magnetite. 
- High-grade hematite ores carry a much higher remanent magnetization than induced magnetization, with an average $Q$-value of about 8. In contrast, the fresh magnetite in BIFs has a lower average $Q$-value of about 0.7 , opposite to that of the high-grade hematite ores.

- Hematite ores with less than $0.1 \%$ magnetite appear to have an exponential correlation between the bulk susceptibility and hematite content in weight percentage. This is different from the commonly accepted linear relationship between the bulk susceptibility and hematite content obtained from synthetic hematite samples.

\section{Acknowledgements}

The Minerals \& Energy Research Institute of WA (MERIWA), BHP Iron Ore, Hamersley Iron, and Robe River Iron Associates are thanked for partly supporting this research. This study was supported by an Overseas Postgraduate Research Scholarship of Commonwealth Government of Australia, and a UWA University Postgraduate Award. Guidance from Professors ZX Li and C Powell was much appreciated.

\section{References}

[1] Borradaile, G.J. and Henry, B. (1997) Tectonic Application of Magnetic Susceptibility and Its Anisotropy. EarthScience Reviews, 42, 49-93. http://dx.doi.org/10.1016/S0012-8252(96)00044-X

[2] Borradaile, G.J. (1988) Magnetic Susceptibility, Petrofabrics and Strain. Tectonophysics, 156, 1-20. http://dx.doi.org/10.1016/0040-1951(88)90279-X

[3] Guo, W. (1999) Magnetic Petrophysics and Density Investigations of the Hamersley Province, Western Australia: Implications for Magnetic and Gravity Interpretation. The University of Western Australia, Perth.

[4] Guo, W.W. Magnetic Mineralogical Characteristics of Hamersley Iron Ores in Western Australia. Journal of Applied Mathematics and Physics. (In Press)

[5] Hounslow, M.W. and Maher, B.A. (1999) Source of the Climate Signal Recorded by Magnetic Susceptibility Variations in Indian Ocean Sediments. Journal of Geophysical Research, 104, 5047-5061. http://dx.doi.org/10.1029/1998JB900085

[6] Balla Ondoa, A., Ngos III, S., Ndjeng, E., Abolo, A. and N’Nanga, A. (2014) Contribution of the Magnetic Susceptibility to the Characterization of the Babouri-Figuil Cretaceous Basin. Open Journal of Soil Science, 4, 272-283. http://dx.doi.org/10.4236/ojss.2014.48029

[7] Thompson, R. and Oldfield, E. (1986) Environmental Magnetism. Allen and Unwin, London. http://dx.doi.org/10.1007/978-94-011-8036-8

[8] Guo, W., Dentith, M.C., Bird, R.T. and Clark, D.A. (2001) Systematic Error Analysis of Demagnetisation and Implications for Magnetic Interpretation. Geophysics, 66, 562-570. http://dx.doi.org/10.1190/1.1444947

[9] Guo, W.W., Li, Z.X. and Dentith, M.C. (2011) Magnetic Petrophysical Results from the Hamersley Basin and Their Implications for Interpretation of Magnetic Surveys. Australian Journal of Earth Sciences, 58, 317-333. http://dx.doi.org/10.1080/08120099.2011.552984

[10] Chen, C.W. (1977) Magnetism and Metallurgy of Soft Magnetic Materials. North-Holland, Amsterdam.

[11] Merrill, R.T., McElhinny, M.W. and McFadden, P.L. (1996) The Magnetic Field of the Earth: Paleomagnetism, the Core, and the Deep Mantle. Academic Press, San Diego.

[12] Tarling, D.H. and Hrouda, F. (1993) The Magnetic Anisotropy of Rocks. Chapman \& Hall, London.

[13] Dunlop, D.J. and Ozdemir, O. (1997) Rock Magnetism. Cambridge University Press, Cambridge. http://dx.doi.org/10.1017/CBO9780511612794

[14] Butler, R.F. (1992) Paleomagnetism. Blackwell Scientific Publications, Boston.

[15] Clark, D.A. and Schmidt, P. (1986) Magnetic Properties of the Banded-Iron Formations of the Hamersley Group, WA. CSIRO Division of Mineral Physics, AMIRA Report 1638.

[16] Guo, W.W. (2010) A Novel Application of Neural Networks for Instant Iron-Ore Grade Estimation. Expert Systems with Applications, 37, 8729-8735. http://dx.doi.org/10.1016/j.eswa.2010.06.043

[17] Li, M.M., Guo, W., Verma, B., Tickle, K. and O’Connor, J. (2009) Intelligent Methods for Solving Inverse Problems of Backscattering Spectra with Noise: A Comparison between Neural Networks and Simulated Annealing. Neural Computing and Applications, 18, 423-430. http://dx.doi.org/10.1007/s00521-008-0219-x 